\title{
OPEN Synthesis, characterization and heavy metal removal efficiency of nickel ferrite nanoparticles (NFN's)
}

\author{
Waheed Ali Khoso ${ }^{1}$, Noor Haleem ${ }^{1 凶}$, Muhammad Anwar Baig ${ }^{1}$ \& Yousuf Jamal ${ }^{1,2}$
}

The heavy metals, such as $\mathrm{Cr}(\mathrm{VI}), \mathrm{Pb}(\mathrm{II})$ and $\mathrm{Cd}(\mathrm{II})$, in aqueous solutions are toxic even at trace levels and have caused adverse health impacts on human beings. Hence the removal of these heavy metals from the aqueous environment is important to protect biodiversity, hydrosphere ecosystems, and human beings. In this study, magnetic Nickel-Ferrite Nanoparticles (NFNs) were synthesized by co-precipitation method and characterized using X-Ray Diffraction (XRD), Energy Dispersive Spectroscopy (EDS) and Field Emission Scanning Electronic Microscopy (FE-SEM) techniques in order to confirm the crystalline structure, composition and morphology of the NFN's, these were then used as adsorbent for the removal of $\mathrm{Cr}(\mathrm{VI}), \mathrm{Pb}$ (II) and $\mathrm{Cd}(\mathrm{II})$ from wastewater. The adsorption parameters under study were $\mathrm{pH}$, dose and contact time. The values for optimum removal through batchadsorption were investigated at different parameters $(\mathrm{pH} 3-7$, dose: 10, 20, 30, 40 and $50 \mathrm{mg}$ and contact time: $30,60,90$, and $120 \mathrm{~min}$ ). Removal efficiencies of $\mathrm{Cr}(\mathrm{VI}), \mathrm{Pb}$ (II) and $\mathrm{Cd}(\mathrm{II})$ were obtained $89 \%, 79 \%$ and $87 \%$ respectively under optimal conditions. It was found that the kinetics followed the pseudo second order model for the removal of heavy metals using Nickel ferrite nanoparticles.

Heavy metals ions deteriorate the groundwater quality to the level of being hazardous ${ }^{1}$ and non-biodegradable nature to meet the local environmental standards before it is recycled or returned to major resources of water ${ }^{2}$. Heavy metals cause serious problem due to their toxic effect on humans and the environment ${ }^{3}$. Unlike organic pollutants because they are bio-degradable but heavy metal do not degrade into harmless end products ${ }^{4,5}$. Industries including; mining, paints and pigment, fertilizer, textile, metal plating, batteries and electronic waste are the major sources that discharge heavy metals directly or indirectly into the environment ${ }^{1,6}$.

The United States Environmental Protection Agency (US EPA) has established maximum contaminant level (MCL) for different heavy metals beyond which these are considered to be toxic for human consumption ${ }^{7}$ and the values for Chromium ${ }^{8}$, Lead and Cadmium are $0.05,0.006$ and $0.01 \mathrm{mg} / \mathrm{L}$ respectively ${ }^{9-11}$. Even at low concentrations their ions have been found toxic to aquatic flora and fauna. Since last few decades, various techniques such as chemical precipitation, membrane separation, electrolytic separation, ion exchange and adsorption have been used to reduce these toxic metals from aqueous medium ${ }^{12}$. Especially the role of nanomaterials is emerging as an effective adsorbent for wastewater treatment ${ }^{13,14}$.

Adsorption technique has been widely used for the removal of heavy metals. Several researches have shown that nanomaterials are effective sorbents for the removal of heavy metal ions from wastewater ${ }^{2,15}$. Adsorption with nanomaterials is a finest method for heavy metal removal based on the physical interaction between metal ions and sorbents ${ }^{7}$. Adsorbents based on nickel ferrite nanoparticles (NFNs) is seen as potential for heavy metal removal in view of its low cost, high efficiency ${ }^{7}$, and simplicity of operation for removing trace levels of heavy metal ions ${ }^{16,17}$. Furthermore, the sludge produced from the adsorption process is also considered to be simpler for disposal than that from other processes ${ }^{18,19}$.

Due to their small size and large surface area, nanomaterials have strong adsorption capacities and reactivity ${ }^{20}$. Moreover, the mobility of nanomaterials in solution is high. Heavy metals, organic pollutants, inorganic anions and bacteria have been reported to be successfully removed by various kinds of nanomaterials ${ }^{21}$. Recently, research on Nickel Ferrite Nanoparticles (NFNs) have attained considerable attention ${ }^{22}$ because of the difference of their physical and chemical properties from those of the free atoms or molecules ${ }^{8,16,23}$ as well as from

${ }^{1}$ Institute of Environmental Sciences and Engineering (IESE), School of Civil and Environmental Engineering (SCEE), National University of Sciences and Technology, Islamabad 44000, Pakistan. ${ }^{2}$ Institute of Chemical Engineering \& Technology, University of Punjab, Lahore 54590, Pakistan. ${ }^{\circledR}$ email: nhaleem@iese.nust.edu.pk 
the properties of the bulk solids and have wide range of potential applications. Due to its typical ferromagnetic properties, low conductivity, lower eddy current losses and high electrochemical stability. Nickel ferrite are reported as one of the multifaceted significantly soft ferrite materials. The site of the divalent cations $\left(\mathrm{Ni}^{2+}\right)$ is homologous to the magnetic properties in the crystal structure of the nickel ferrite. Moreover, nickel ferrite shows super-paramagnetic property and it has diverse applications such as gas-sensor, catalyst, magnetic fluids and magnetic storage systems ${ }^{24}$.

For synthesis of various metal-oxide nanoparticles, several chemical methods have been reported in literature such as hydrothermal, reverse micelle, solvothermal, sol-gel, polymeric precursor and co-precipitation ${ }^{19}$. This paper aims to report the synthesis of Nickel Ferrite Nanoparticles $\left(\mathrm{NiFe}_{2} \mathrm{O}_{4}\right)$ by using co-precipitation method. The potential use of these nanoparticles as adsorbent ${ }^{22}$ for removal of heavy metals (Cr(VI), $\mathrm{Pb}$ (II) and Cd(II)) from synthetic wastewater was investigated particularly ${ }^{25}$. For this purpose, the influence of $\mathrm{pH}$, contact time and initial does on the sorption capacity of NFNs has been studied. We have also investigated the different effect of $\mathrm{pH}$ on adsorption of $\mathrm{Cr}(\mathrm{VI})$ and $\mathrm{Pb}$ and $\mathrm{Cd}$. Pseudo second order kinetic model were used for the surface adsorption to explain the adsorption kinetics most effectively that involves chemisorption, where the removal from a solution is due to physicochemical interactions between the two phases ${ }^{26}$.

\section{Materials and methods}

Materials. Material for synthesis of NFNs. Following chemicals were used for the synthesis of nickel-ferrite nanoparticles NFN's.

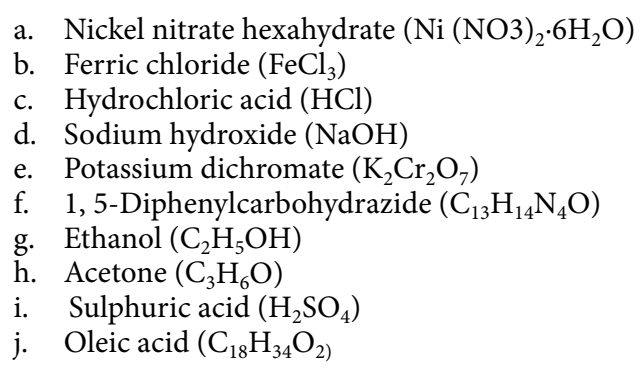

All the chemicals used in synthesis of NFN's were of analytical grade.

Preparation of nickel-ferrite nanoparticles (NFNs). Magnetic NFN's were prepared by the co-precipitation method in which nickel nitrate and ferric chloride salts are mixed in 1:2 molar ratios before being extracted through precipitation at high $\mathrm{pH}$.

Nickel nitrate hexahydrate $\left(\mathrm{Ni}\left(\mathrm{NO}_{3}\right)_{2} \cdot 6 \mathrm{H}_{2} \mathrm{O}\right)$ solution. In order to prepare $0.2 \mathrm{M}$ solution, $2.909 \mathrm{~g}$ of nickel nitrate hexahydrate was dissolved in $50 \mathrm{ml}$ distillated water to make $50 \mathrm{ml}$ of $0.2 \mathrm{M}$ solution and $5.406 \mathrm{~g}$ of Ferric chloride salt $\left(\mathrm{FeCl}_{3}\right)$ was dissolved in distillated water to make $50 \mathrm{ml}$ of $0.4 \mathrm{M}$ solution of Ferric Chloride $\left(\mathrm{FeCl}_{3}\right)$. Both solutions were mixed properly on magnetic stirrer at $200 \mathrm{rpm}$ homogenously at $80{ }^{\circ} \mathrm{C}$ for $30 \mathrm{~min}$, then placed outside room temperature. Sodium hydroxide $(12 \mathrm{~g})$ was mixed in $100 \mathrm{ml}$ distilled water to make $100 \mathrm{ml}$ of $2.0 \mathrm{M}$ solution of mineralized sodium hydroxide $(\mathrm{NaOH})$, which was then added drop wise using syringe as precipitating agent until the solution gained required $\mathrm{pH}$ of $8-9$, while constantly stirred at $400 \mathrm{rpm}$ and maintained at a temperature of $70 \pm 5{ }^{\circ} \mathrm{C}$ for $2 \mathrm{~h}$ till brown precipitates were formed. After that, the stirrer was switched off and the magnetic particles settled gradually. The brown precipitate product was cooled at room temperature and the precipitated solution was washed several times with distilled water and neutralized with ethanol $\left(\mathrm{C}_{2} \mathrm{H}_{5} \mathrm{OH}\right)$ to eliminate unwanted impurities from the sample by centrifugation at $4000 \mathrm{rpm}$. The obtained substance was placed in an oven at $70{ }^{\circ} \mathrm{C}$ for $24 \mathrm{~h}$, and after drying, the dried nano powder was ground and calcined at $350-550^{\circ} \mathrm{C}$ for $3 \mathrm{~h}$ in a muffle furnace to obtain pure $\mathrm{NiFe}_{2} \mathrm{O}_{4}$, which was then crushed by pestle to obtain the final product in a fine powder form.

Characterization of nanoparticles. For the purpose of characterization following three techniques were employed to verify size of synthesized NFNs.

X-Ray diffraction (XRD). X-Ray diffraction (XRD, JEOL JDX-II) was used to find out the crystalline phase and size of nanoparticles using the Shimadzu-7000 X-ray diffractometer with monochromatized CuKa radiation ${ }^{27}$. The measurement was performed in the range from $20^{\circ}$ to $80^{\circ}$.

Field emission scanning electron microscope (FE-SEM). The topography and morphology of the Nickel-ferrite nanoparticles (NFN's) was carried out using scanning electron microscope (JEOL JSM-6490) at high magnifications. To avoid the charging effect samples were coated with gold for SEM analysis.

Energy dispersive spectroscopy (EDS). Energy-dispersive spectroscopy (EDS, JEOL JSM 6490A) technique was used to determine the elemental composition of selected area on the surface of sample. 


\begin{tabular}{|l|l|l|l|l|}
\hline Dose/pH & pH levels maintained $(\mathbf{3}, \mathbf{4}, \mathbf{5}, \mathbf{6}$ and $\mathbf{7})$ \\
\hline Adsorbent dose (mg) applied at each pH level & $10,20,30,40,50$ & $10,20,30,40,50$ & $10,20,30,40,50$ & $10,20,30,40,50$ \\
\hline Contact time (min) & 30 & 60 & 90 & 120 \\
\hline
\end{tabular}

Table 1. Experimental set up for metals adsorption from synthetic wastewater.

Determination of heavy metal concentrations. UV/Vis Spectrophotometer with quartz cell was used for the detection and quantization limits of $\mathrm{Cr}(\mathrm{VI})$ by measuring absorbance values at the wavelength of maximum absorbance at $540 \mathrm{~nm}$ using the T60 PG instrument, Calibration curves were created using reagent manufacturer for simple quantitative determinations.

Preparation of stock solutions for adsorption study. The Cr (VI) stock solution of $5 \mathrm{mg} / \mathrm{L}$ was prepared by dissolving $0.1414 \mathrm{~g}$ of potassium dichromate $\left(\mathrm{K}_{2} \mathrm{Cr}_{2} \mathrm{O}_{7}\right)$ in distilled water and diluted to $100 \mathrm{~mL} ; 1.00 \mathrm{~mL}=500 \mu \mathrm{g}$ of Cr. This was further diluted to create another standard stock solution of $0.05 \mathrm{mg} / \mathrm{L}(100 \mathrm{~mL}=0.05 \mathrm{mg} / \mathrm{L}$ of chromium); this stock solution was used for adsorption experiments and was then analyzed using UV/Vis spectrophotometer. Following the same above procedure of chromium solution for preparation of lead stock solution by dissolving $0.15985 \mathrm{~g}$ of Lead Nitrate $\left[\mathrm{Pb}\left(\mathrm{NO}_{3}\right)\right]$ in distilled water and diluted to $100 \mathrm{~mL}$ to prepare; $(1.00 \mathrm{~mL}=5 \mathrm{ppm}$ of $\mathrm{Pb})$. The solutions with $5 \mathrm{mg} / \mathrm{L}$ concentrations of the lead was prepared by dilution of stock solution with ultrapure water, producing a $5 \mathrm{mg} / \mathrm{L}$ lead standard stock solution of $1000 \mathrm{ml}$. This was further diluted to create another standard stock solution of $0.5 \mathrm{mg} / \mathrm{L}(10 \mathrm{~mL}=0.5 \mathrm{ppm}$ of lead); this stock solution was used for adsorption experiments and analyzed in Atomic Adsorption Spectrophotometer (AAS).

Preparation of cadmium stock solution by dissolving $0.2744 \mathrm{~g}$ of Lead Nitrate $\left(\mathrm{Pb}\left(\mathrm{NO}_{3}\right)\right)$ in distilled water and diluted to $100 \mathrm{~mL}$ was achieved. to prepare. The solution with $5 \mathrm{ppm}$ concentrations of cadmium was prepared by dilution of the stock solution with ultrapure water, producing a $5 \mathrm{mg} / \mathrm{L}$ cadmium standard stock solution of $1000 \mathrm{ml}$. This was further diluted to create another standard stock solution of $0.5 \mathrm{mg} / \mathrm{L}$; this stock solution was used for adsorption experiments and analyzed in Atomic Adsorption Spectrophotometer (AAS).

Preparation of calibration and standard curve for chromium detection. Standard method (3500$\mathrm{CR}$ ) was used to determine $\mathrm{Cr}$ (VI) in prepared solution using UV/Visible spectrophotometer. For this reason, UV-Vis spectrum of a dye Diphenyl carbazide (DPC) was recorded for determining Cr (VI) in prepared solution to validate the wavelength of maximum absorbance at $540 \mathrm{~nm}$, which follows the standard method. The calibration curve was developed at $\lambda$-max $540 \mathrm{~nm}$ using serial dilutions starting from 0.5 to $5 \mu \mathrm{g} / \mathrm{L}$ five samples of different volume of prepared solution as shown in Fig. 2.

Prepared five samples $S_{1}, S_{2}, S_{3}, S_{4}$ and $S_{5}$ of different volume $1,2,5,7$ and $10 \mathrm{~mL}$ respectively of a $5 \mu \mathrm{g} / \mathrm{L} \mathrm{Cr}$ and $\mathrm{pH}$ were adjusted to $2.0 \pm 5$. Transfer of solution to $100 \mathrm{~mL}$ volumetric flask and were adding three drops of Phosphoric acid $\left(\mathrm{H}_{3} \mathrm{PO}_{4}\right)$ plus adding of $2 \mathrm{~mL}$ of prepared 1,5-diphhenylcarbazide solution and mixed, let stand 5 to $10 \mathrm{~min}$ for full color development. Transfer an appropriate portion to absorption cell and measure its absorbance at $540 \mathrm{~nm}$ wavelength in a spectrophotometer.

Adsorption experiments batch study. The solutions having $5 \mathrm{mg} / \mathrm{L}$ concentrations of $\mathrm{Cr}(\mathrm{VI})$ was prepared by dilution of the stock solution using ultrapure water. Adsorption studies were carried out by mixing 10, 20, 30, 40 and $50 \mathrm{mg}$ of $\mathrm{Ni}-\mathrm{Fe}_{2} \mathrm{O}_{4}$ adsorbent with $50 \mathrm{~mL} \mathrm{Cr}(\mathrm{VI})$ solutions of $5 \mathrm{mg} / \mathrm{L}$. The solution was mixed over magnetic stirrer at $200 \mathrm{rpm}$ with different $\mathrm{pH}$ and contact time, 3, 4, 5, 6 and 7 and 30, 60, 90, and $120 \mathrm{~min}$ respectively as shown in Table 1 . The $\mathrm{pH}$ values of $\mathrm{Cr}(\mathrm{VI})$ solutions were adjusted by using $1 \mathrm{~mol} / \mathrm{L} \mathrm{HCl}$ and $1 \mathrm{~mol} / \mathrm{L} \mathrm{NaOH}$ as reagents.

Adsorption was measured by using measuring $50 \mathrm{~mL}$ of the synthetic wastewater sample and poured into a $100 \mathrm{~mL}$ Backers. 10, 20, 30, 40 and $50 \mathrm{mg}$ of the synthesized nickel nanoparticles were added to different backers containing $50 \mathrm{~mL}$ of synthetic wastewater. The backers containing the adsorbent and the synthetic wastewater were placed on a magnetic stirrer at $200 \mathrm{rpm}$ at room temperature for a period of $120 \mathrm{~min}$ to ensure equilibrium. The suspension was filtered using 0.22-micron filter paper. UV/Vis spectrophotometer and Atomic adsorption spectro-photometer (AAS) were used to analyze the concentration of the different metal ions present in the filtrate. The amount of metal ions adsorbed by the adsorbent was evaluated and following formula was used to calculate the percentage removal.

$$
\mathrm{E}=\mathrm{C}_{\mathrm{o}}-\mathrm{C}_{\mathrm{e}} / \mathrm{C}_{\mathrm{o}} \times 100
$$

where $(\mathrm{E} \%)$ is the ratio of difference in metal concentration before and after adsorption.

\section{Results and discussion}

Characterization of nanoparticles. The X-ray diffraction patterns of the synthesized nickel ferrite nanoparticles (NFN's) are shown in Fig. 1. XRD spectrum made it clear that sample has single spinal shape with good crystallinity. The NFN's contained no impurity peaks within the limit of X-ray detection. The significant peak broadening indicates the ultra-fine nature of the sample. The average crystalline diameter (D) was calculated by Scherer's equation $(D=0.9 \lambda / \beta \cos \theta)$ as $30.254 \mathrm{~nm}$.

The peaks pattern shown in Fig. 1 of Nickel ferrite are intense and sharp, representing good crystallinity of the prepared sample. The peaks were found to be at $2 \theta$ values of $29.84807^{\circ}, 31.63629^{\circ}, 35.27^{\circ}, 45.37836^{\circ}$ and 


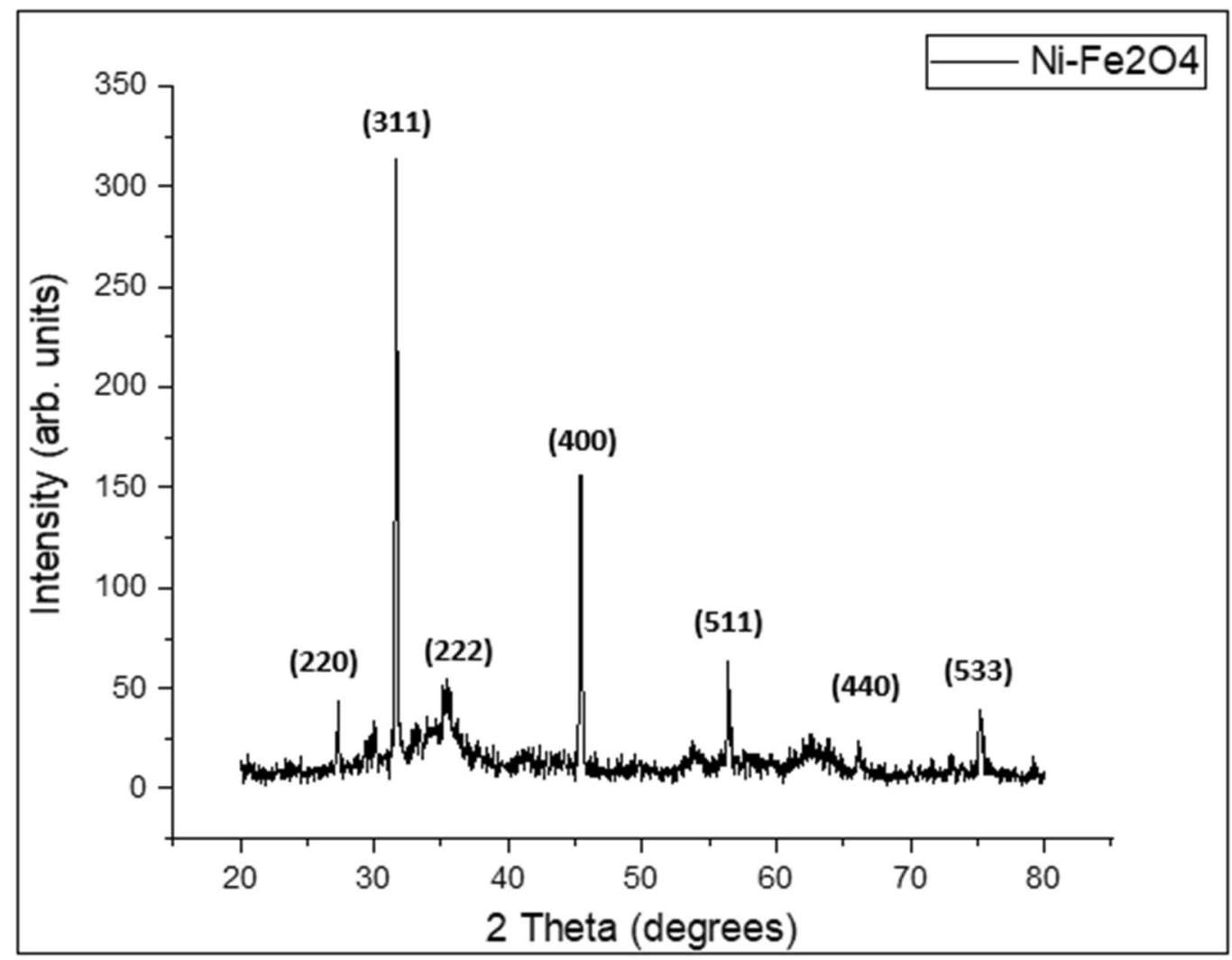

Figure 1. XRD pattern of synthesized nickel ferrite nanoparticles.

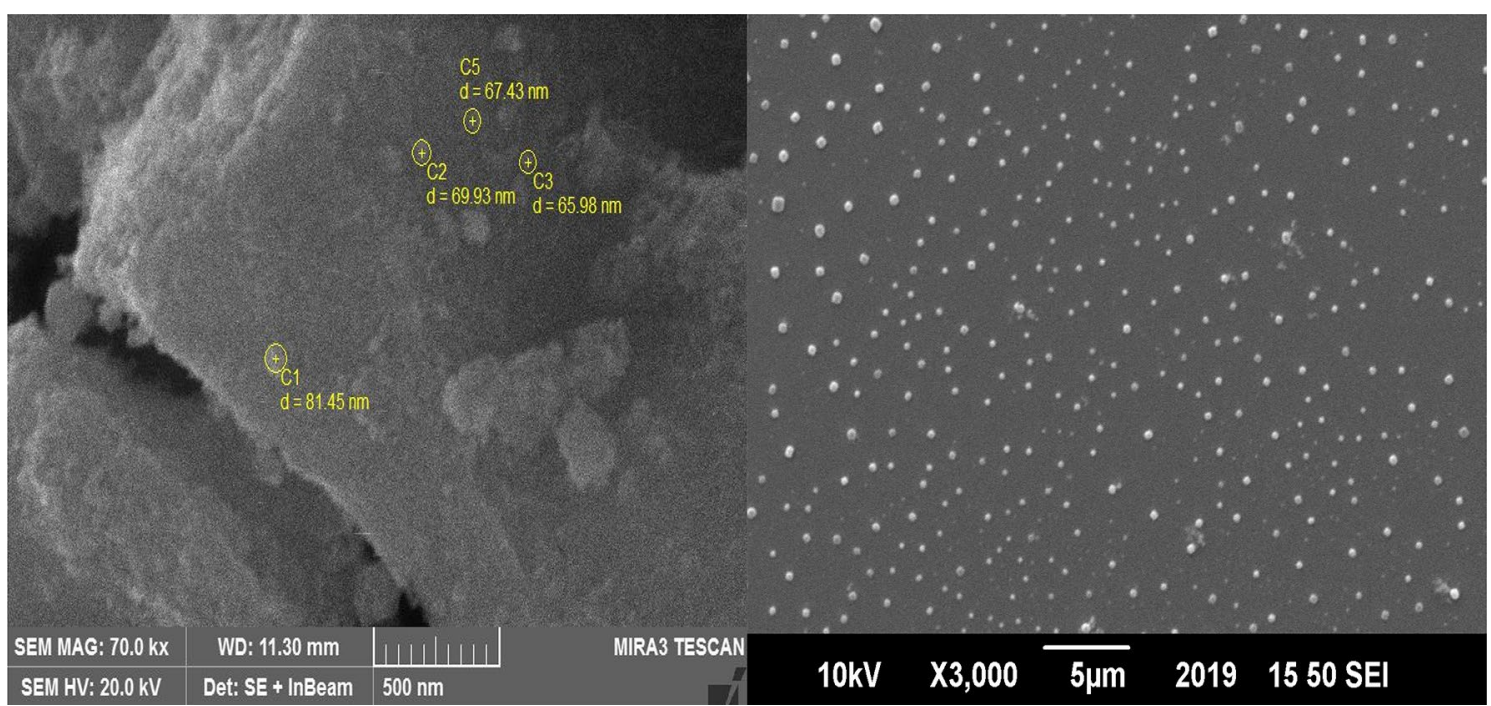

Figure 2. SEM images of $\mathrm{NiFe}_{2} \mathrm{O}_{4}$ nanoparticles.

$56.43597^{\circ}$ corresponded to the crystal planes of (220), (311), (222), (400), (511), (440) and (533) in the pattern of Nickel ferrite, this proved the formation of NFN's spinel phase. No other peaks are found that indicating the synthesized sample consists of high purity $\mathrm{NiFe}_{2} \mathrm{O}_{4}$. By applying the Scherer's formula $\mathrm{D}=0.9 \lambda / \beta \cos \theta$, size of the crystallite was calculated. Where $\mathrm{D}$ is the crystallite size, $\beta$ is the line broadening at the full width at half maximum (FWHM) of the most intense peak (311), $\mathrm{K}$ is Scherrer constant, $\theta$ is the Bragg's angle and $\lambda$ is the $\mathrm{X}$-ray wavelength. The average crystallite size of nickel ferrite nanoparticles was estimated to be $30.254 \mathrm{~nm}$.

Figure 2 depicts the field emission scanning electron micro graph (FE-SEM) of magnetic $\mathrm{NiFe}_{2} \mathrm{O}_{4}$. nanoparticles. The SEM image shows that the nanoparticles have sizes of less than $100 \mathrm{~nm}$ and they are dense and frequently distributed with-in the whole area. Moreover, aggregation of small particles was also observed. Thus, it has been confirmed and made clear by SEM analysis that spherical shape materials are formed as a result of tiny particle 


\begin{tabular}{|l|l|l|}
\hline Element & Weight \% & Atomic \% \\
\hline O K & 25.79 & 44.79 \\
\hline $\mathrm{Na} \mathrm{K}$ & 18.22 & 22.03 \\
\hline $\mathrm{Cl} \mathrm{K}$ & 18.96 & 14.86 \\
\hline Fe K & 32.69 & 16.27 \\
\hline $\mathrm{Ni} \mathrm{K}$ & 4.34 & 2.06 \\
\hline
\end{tabular}

Table 2. Relative elemental mass of synthesized NFN's.

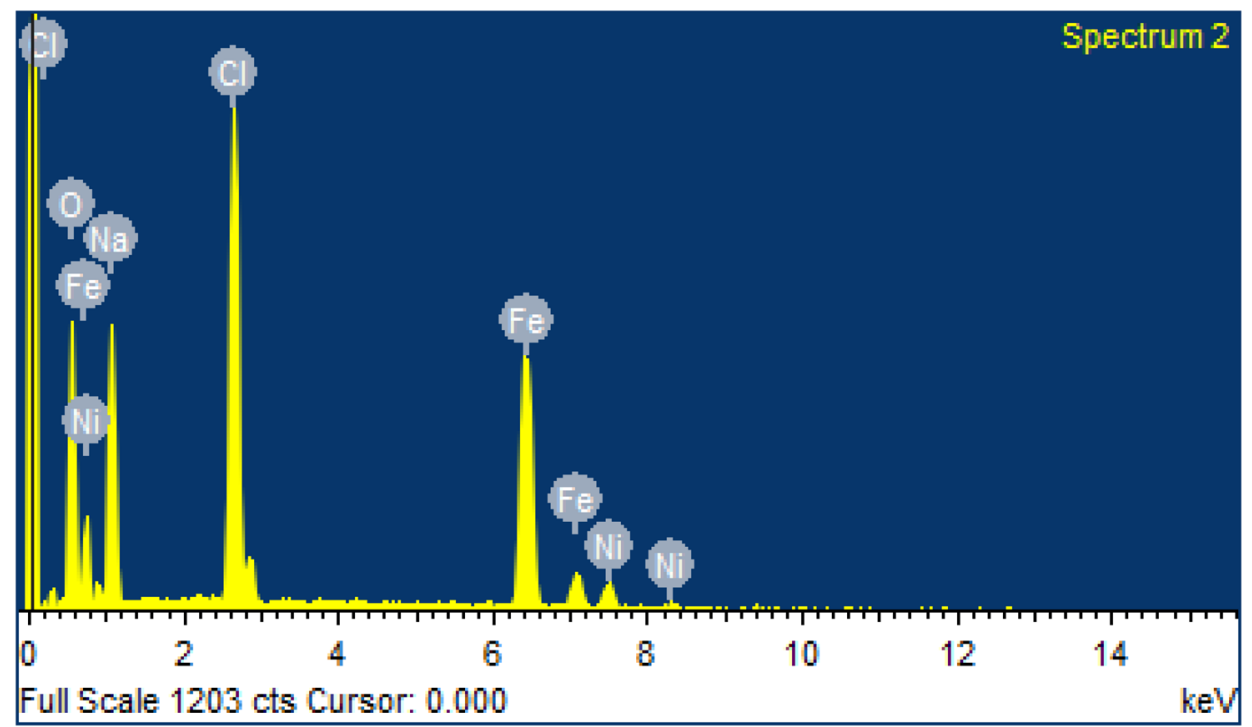

Figure 3. EDS-elemental composition of $\mathrm{NiFe}_{2} \mathrm{O}_{4}$ nanoparticles.

aggregation. The presence of pore free crystallites on the surface is due to agglomeration of small particles as the nanomaterials possess high surface energies. The average size range of nickel ferrite was found to be $30.254 \mathrm{~nm}$.

Energy dispersive X-ray spectroscopy (EDS) is the technique use for the determinations of elemental composition or chemical characterization of sample. Table 2 shows relative elemental mass of different elements such as nickel, iron, and oxygen present in the NFN's sample. While there is no any alien element or impurity is present in the prepared sample.

The EDS spectrum is shown in Fig. 3. Peaks corresponding to chlorine, nickel, iron and oxygen were found in the spectrum. A sharp peak of chlorine was observed due to its reactivity. Chlorine tends to react with compounds including metal-metal, metal-hydrogen or metal-carbon bonds to form metal-chlorine bonds as reported ${ }^{28}$.

Preparation of calibration curves for analysis. A calibration curve was developed at $\lambda$-max $540 \mathrm{~nm}$ using serial dilutions starting from 0.5 to $5 \mu \mathrm{g} / \mathrm{L}$ of solution as shown in Fig. 4 and summarized in Table 3. The calibration curve of $\mathrm{Cr}(\mathrm{VI})$ was prepared from five different concentrations $0.5 \mu \mathrm{g} / \mathrm{L}, 1 \mu \mathrm{g} / \mathrm{L}, 2.5 \mu \mathrm{g} / \mathrm{L}$, $3.5 \mu \mathrm{g} / \mathrm{L}$ and $5 \mu \mathrm{g} / \mathrm{L}$ standards. The linear calibration curve with the equation absorbance $=0.0867 \mathrm{x}+0.0272$, where absorbance units are in milli absorbance and concentration is measured in $\mu \mathrm{g} / \mathrm{L}$, gave a correlation coefficient R2 $\geq 0.9996$.

A calibration equation $(y=0.0867 \mathrm{x}+0.0272, R 2=0.9996$, where $\mathrm{y}$ is absorbance and $\mathrm{x}$ is concentration in ppm or $\mu \mathrm{g} / \mathrm{l})$ derived from a calibration curve was plotted from standards $(0.5 \mu \mathrm{g} / \mathrm{L}, 1 \mu \mathrm{g} / \mathrm{L}, 2.5 \mu \mathrm{g} / \mathrm{L}, 3.5 \mu \mathrm{g} / \mathrm{L}$, and $5 \mu \mathrm{g} / \mathrm{L}$ ) for the quantization of $\mathrm{Cr}(\mathrm{VI})$ in wastewater samples. However, due to the low sensitivity to low $\mathrm{Cr}$ (VI) concentrations and low detection limits of $\mathrm{Cr}(\mathrm{VI})$ in synthesized samples, light pink color developed with 1,5-diphenylcarbazide. Synthesized samples were spiked with $1 \mathrm{~mL}, 2 \mathrm{~mL}, 5 \mathrm{~mL}, 7 \mathrm{~mL}$ and $10 \mathrm{~mL}$ of a $5 \mu \mathrm{g} / \mathrm{L}$ $\mathrm{Cr}(\mathrm{VI})$ standard. Figures 4 show the spiked curves that were used for the quantization of $\mathrm{Cr}(\mathrm{VI})$ in wastewater samples.

Adsorption batch study. Effect of contact time for removal of heavy metals. The effect of contact time on the removal efficiency of $\mathrm{Cr}(\mathrm{VI}), \mathrm{Pb}$ (II) and $\mathrm{Cd}(\mathrm{II})$ ions using synthesized nickel ferrite nanoparticles (NFN's) were studied at room temperature and the obtained results are shown in Fig. 5. 


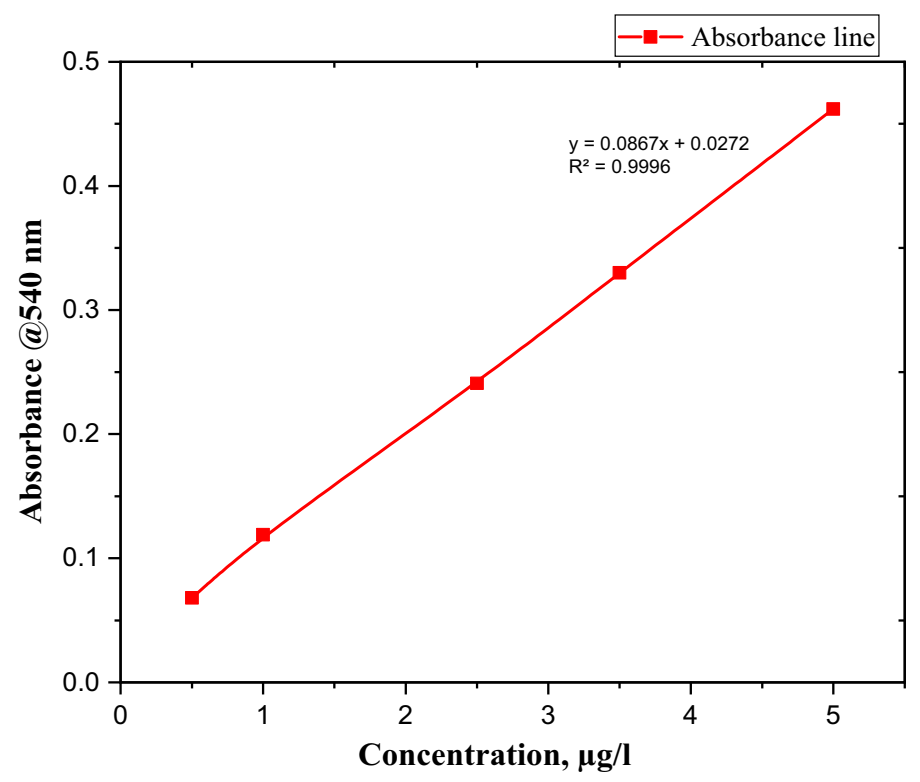

Figure 4. Standard calibration curve spiked with different volumes at $\lambda$-max $540 \mathrm{~nm}$.

\begin{tabular}{|l|l|l|l|}
\hline Samples run & Volume $(\mathbf{m L})$ & Absorbance $(\mathbf{5 4 0} \mathbf{~ n m})$ & Concentration $(\boldsymbol{\mu g} / \mathbf{L})$ \\
\hline $\mathrm{S}_{1}$ & 1 & 0.068 & 0.5 \\
\hline $\mathrm{S}_{2}$ & 2 & 0.119 & 1 \\
\hline $\mathrm{S}_{3}$ & 5 & 0.241 & 2.5 \\
\hline $\mathrm{S}_{4}$ & 7 & 0.33 & 3.5 \\
\hline $\mathrm{S}_{5}$ & 10 & 0.462 & 5 \\
\hline
\end{tabular}

Table 3. Absorbance of five standard synthesized samples of a $5 \mu \mathrm{g} / \mathrm{L} \mathrm{Cr}(\mathrm{VI})$ at $540 \mathrm{~nm}$.

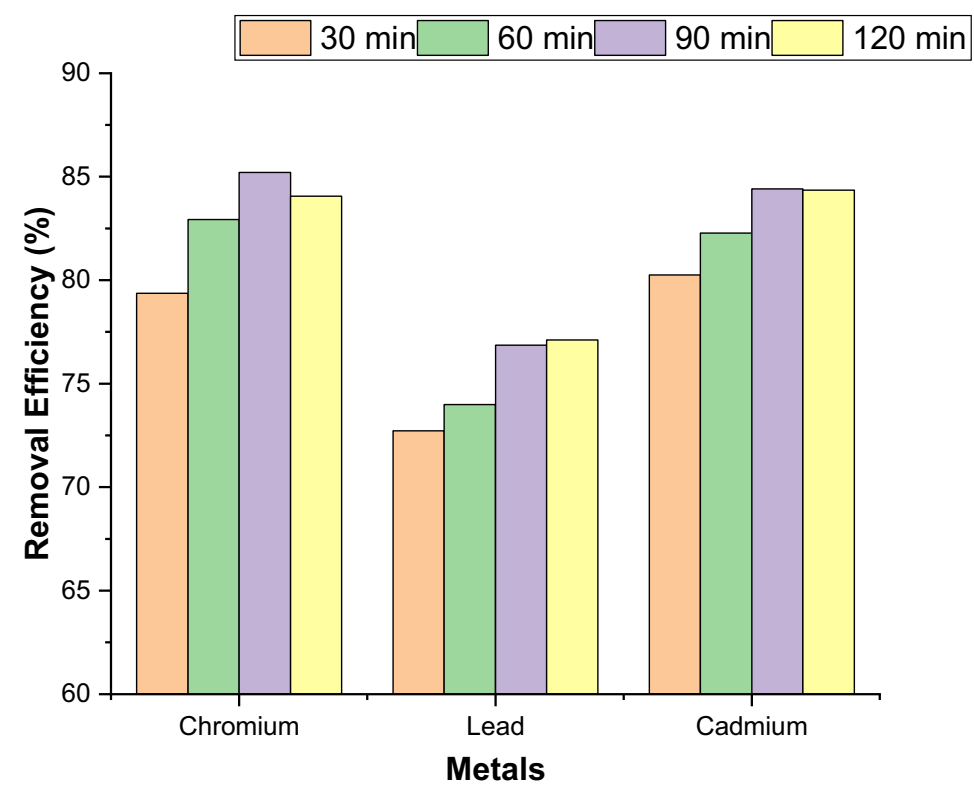

Figure 5. Effect of contact time for removal of $\mathrm{Cr}(\mathrm{VI}), \mathrm{Pb}(\mathrm{II})$, and $\mathrm{Cd}(\mathrm{II})$ by adsorption. 


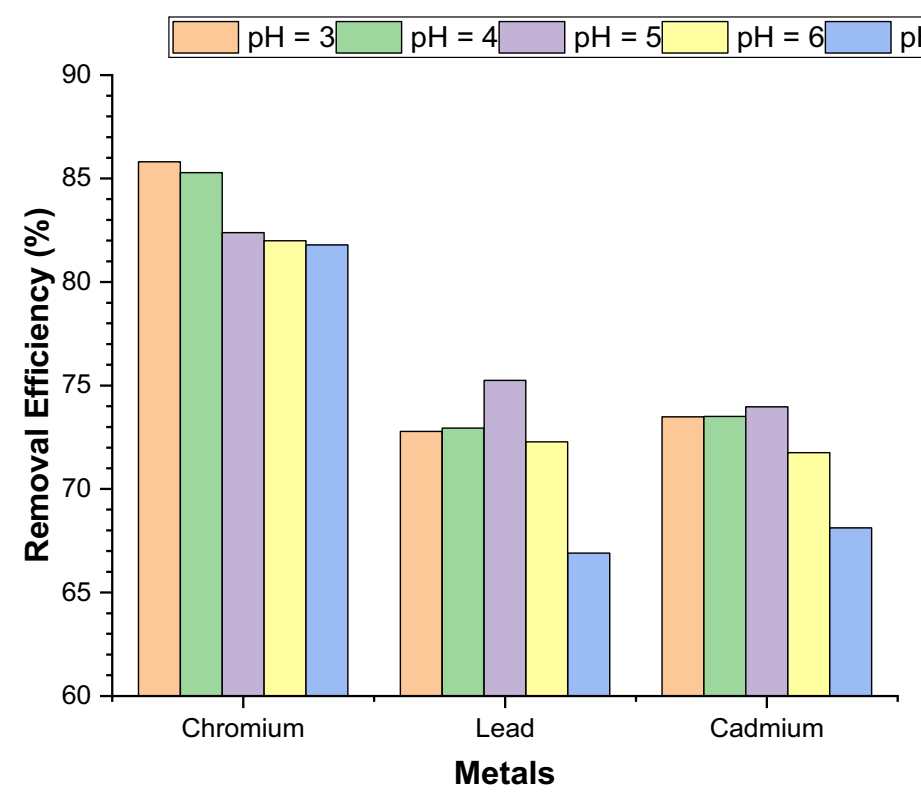

Figure 6. Effect of $\mathrm{pH}$ for removal of $\mathrm{Cr}(\mathrm{VI}), \mathrm{Pb}(\mathrm{II})$, and $\mathrm{Cd}(\mathrm{II})$ by adsorption.

It was observed that, the removal of metal ions increases with increase in contact time and attained equilibrium level at $90 \mathrm{~min}$, after which further increase in time did not bring any further improvement for the removal of metal ions, rather resulted in desorption of metal ions from the adsorbent surface. Nickel ferrite nanoparticles shows maximum removal efficiency of $85.21 \%$ for $\mathrm{Cr}(\mathrm{VI})$ ions in $90 \mathrm{~min}, 77.41 \%$ for $\mathrm{Pb}$ (II) ions in $120 \mathrm{~min}$, and $84.45 \%$ for Cd(II) ions in 90 min applied constant (e.g. $10 \mathrm{mg}$ ) of adsorbent dosage. The results shown that the different metal ions attained equilibrium at different times and the higher removal efficiency is for the removal of $\mathrm{Cd}(\mathrm{II})$ and lower removal efficiency is for the removal of $\mathrm{Pb}(\mathrm{II})$.

Effect of $\mathrm{pH}$ for removal of heavy metals. The effect of $\mathrm{pH}$ was studied from a range of 3 to 7 under the precise conditions (at optimum contact time 30 to $120 \mathrm{~min} @ 200 \mathrm{rpm}$ shaking speed, with $10 \mathrm{mg}$ of the adsorbent used at room temperature). In all experiment the NFN's dose (10 mg) was kept constant to assessed effect of $\mathrm{pH}$ on adsorption of metal ions using nickel ferrite nanoparticles (NFN's) is shown in Fig. 6.

The effects of solution $\mathrm{pH}$ on the adsorption of $\mathrm{Cr}(\mathrm{VI}), \mathrm{Pb}(\mathrm{II})$ and $\mathrm{Cd}(\mathrm{II})$ onto NFNs were studied by varying the aqueous solution $\mathrm{pH}$. It was observed that with increased in the $\mathrm{pH}$ from 3 to 7 of the synthetic wastewaters, the removal efficiencies of $\mathrm{Cr}(\mathrm{VI})$ decreased at rate as $\mathrm{pH}$ increased and maximum removal efficiency was obtained at $\mathrm{pH} 3$ as shown in the Fig. 6. Hence, the removal efficiency of chromium gradually decreased as $\mathrm{pH}$ increased. The maximum removal efficiency of Lead and Cadmium was found at pH 5 as shown in the Fig. 6. Nickel ferrite nanoparticles (NFN's) shown maximum removal efficiency of $85.8 \%$ for Cr(VI) ions at pH 3, 75.25\%

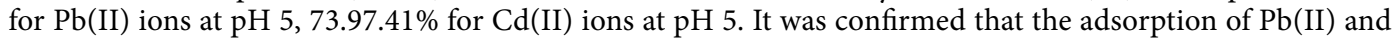
$\mathrm{Cd}(\mathrm{II})$ increased with the increase of $\mathrm{pH}$ value because, at lower $\mathrm{pH}$, more hydrogen ions $\left(\mathrm{H}^{+}\right)$were contained in the system and the high concentration was competitive with both metal ions which causes low adsorption. As the solution $\mathrm{pH}$ increased, the adsorption of metal ions on the NFNs increased due to the decreasing $\mathrm{H}^{+}$ions. These ions acted as a competitor to the positive metal ions for adsorption sites on the surface of the nanocomposite.

Effect of absorbent dosage for removal of heavy metals. Adsorbent dosage was varied from 0.01 to $0.05 \mathrm{~g}$, under the specific condition (contact time of $90 \mathrm{~min}, 200 \mathrm{rpm}$ shaking speed, room temperature and $\mathrm{pH}$ of $3 \mathrm{\&}$ 5) using Nickel ferrite nanoparticles (NFN's). The relationship between adsorbent dosage and removal efficiency of metal ions from synthesized wastewater are shown in the Fig. 7.

Nickel ferrite nanoparticles (NFN's) shown maximum removal efficiency of $89.8 \%$ for Cr(VI) ions on $30 \mathrm{mg}$ of adsorbent dosage, $79.47 \%$ for $\mathrm{Pb}$ (II) ions on $40 \mathrm{mg}$ and $87.24 \%$ for $\mathrm{Cd}(\mathrm{II})$ ions on $40 \mathrm{mg}$ of adsorbent dosage. The results clearly show that the increased in adsorbent dosage also increases the removal efficiency of metal ions and maximum removal efficiency was attained at a particular adsorbent dosage, until an optimal dosage of $30 \mathrm{mg}$ for $\mathrm{Cr}$ (VI), $40 \mathrm{mg}$ for $\mathrm{Pb}(\mathrm{II})$ and $\mathrm{Cd}(\mathrm{II})$ was reached after which the removal was more or less the same. Starting from $10 \mathrm{mg}$ with an increment of $10 \mathrm{mg}$, the dosage was increased up to $50 \mathrm{mg}$ showing increase removal with increased dosage until the maximum removal is achieved at the $30 \mathrm{mg}$ which is the optimum dosage for removal of $\mathrm{Cr}(\mathrm{VI}), 40 \mathrm{mg}$ for $\mathrm{Pb}(\mathrm{II})$ and $\mathrm{Cd}(\mathrm{II})$. Increasing the percentage of adsorption with adsorbent dose is due to the increase in adsorbent surface area and availability of more adsorption sites, the rate of adsorption, however, decreased with increase in adsorbent dose after the optimal value. This is due to overlapping of adsorption sites as a result of overcrowding of adsorbent particles. When the NFN's were dispersed into synthesized wastewater with high dose of NFN's it resulted decrease adsorption which was the major cause reduction of contact surface of nanoparticles for removal of metal ions. 


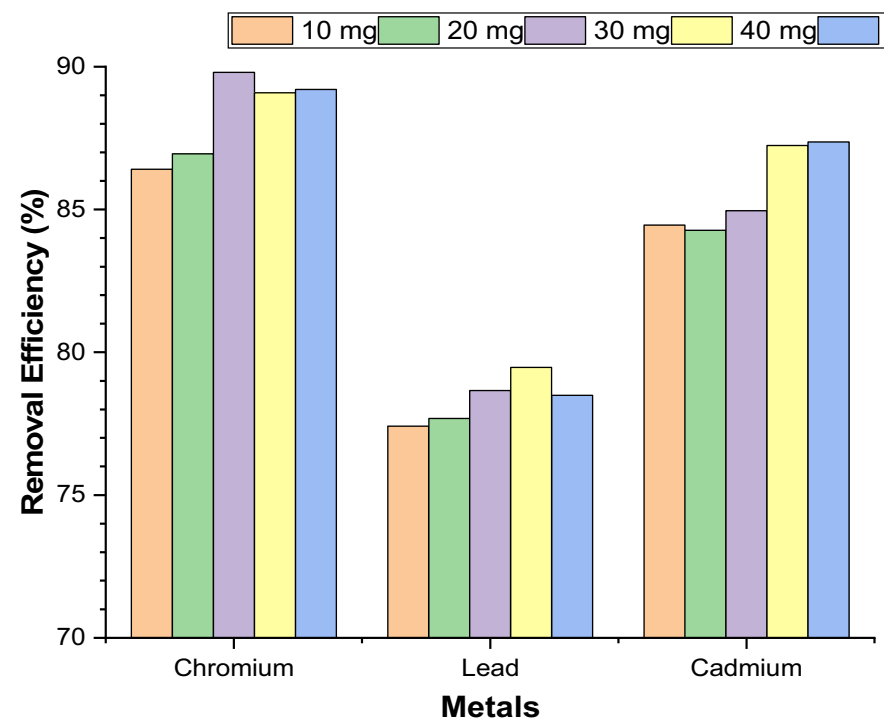

Figure 7. Effect of adsorbent dosage for removal of $\mathrm{Cr}(\mathrm{VI}), \mathrm{Pb}(\mathrm{II})$, and $\mathrm{Cd}(\mathrm{II})$.

\begin{tabular}{|l|l|l|l|l|}
\hline Metal ions & $\mathbf{q}_{\mathbf{e}}$ calculated $(\mathbf{m g} / \mathbf{g})$ & $\mathbf{q}_{\mathbf{e}}$ experimental $(\mathbf{m g} / \mathbf{g})$ & $\mathbf{K}_{\mathbf{2}}(\mathbf{g} / \mathbf{m g} \mathbf{m i n})$ & $\mathbf{R}^{\mathbf{2}}$ \\
\hline Chromium & 21.3025 & 21.5437 & 0.0207 & 0.9995 \\
\hline Lead & 19.2150 & 19.8773 & 0.0148 & 0.9996 \\
\hline Cadmium & 21.1125 & 21.5343 & 0.0198 & 0.9999 \\
\hline
\end{tabular}

Table 4. Sorption capacities at equilibrium and sorption rate coefficients.

Pseudo-second order kinetic model. The obtained results for the equilibrium concentrations and sorption capacities were compared with the forms of Langmuir and Freundlich isotherms, but did not yield a straight line. The results were then compared against a pseudo-second order kinetic model as done is previous studies for heavy metal removal through nickel ferrite nanoparticles. The expression for the pseudo-second order kinetic model is shown below:

$$
\frac{\mathrm{t}}{\mathrm{q}_{\mathrm{t}}}=\frac{1}{\mathrm{~K}_{2} \mathrm{q}_{\mathrm{e}}^{2}}+\frac{\mathrm{t}}{\mathrm{q}_{\mathrm{e}}}
$$

where $\mathrm{t}(\mathrm{min})$ is contact time, $\mathrm{q}_{\mathrm{t}}(\mathrm{mg} / \mathrm{g})$ is the sorption capacity at time $\mathrm{t}, \mathrm{q}_{\mathrm{e}}(\mathrm{mg} / \mathrm{g})$ is the sorption capacity at equilibrium and $\mathrm{K}_{2}(\mathrm{~g} /(\mathrm{mg} \mathrm{min}))$ is the pseudo-second order sorption rate constant ${ }^{26,29,30}$. Sorption capacities at equilibrium and sorption rate coefficients for the adsorption of the three heavy metals through NFN's along with correlation coefficients are summarized in Table 4.

From Table 4, clearly a close agreement among the experimental values and corresponding pseudo-second order kinetic model is observed.

\section{Conclusion}

As a result of this study, low cost spin shaped NFNs using the co-precipitation method were prepared as sorbent for removal of heavy metals. XRD and SEM techniques were used to characterize the synthesized nanostructure materials. XRD analysis indicates that the prepared samples have single phase spinel structure. The SEM image shows that the nanoparticles are spherical, homogeneous and discrete with a particle size around 30-69 nm. These spinel ferrites were found to be efficient for the removal of heavy metals ( $\mathrm{Cr}(\mathrm{VI}), \mathrm{Pb}$ (II) \& $\mathrm{Cd}(\mathrm{II})$ ) from synthetic wastewater by adsorption through NFNs magnetic nanoparticles. In this study, the removal efficiencies of $\mathrm{Cr}(\mathrm{VI}), \mathrm{Pb}(\mathrm{II})$ and $\mathrm{Cd}(\mathrm{II})$ by using NFNs was determined $89 \%, 79 \%$ and $87 \%$ respectively. Optimum dosages of NFNs for the removal of these heavy metals was found to be around $30 \mathrm{mg}$ with generally lower $\mathrm{pH}$ values resulting in higher removal efficiencies. The results reiterate the promise of nanoparticles in general and NFNs in particular, for the removal of heavy metals from wastewater. Therefore, spinel ferrite can be considered as a potential candidate in adsorption chemistry for removal of heavy metals from wastewater.

Received: 26 October 2020; Accepted: 31 December 2020

Published online: 15 February 2021 


\section{References}

1. Hassan, M. M., Haleem, N., Baig, M. A. \& Jamal, Y. Phytoaccumulation of heavy metals from municipal solid waste leachate using diferent grasses under hydroponic condition. Sci. Rep. 10(15802), 2-8. https://doi.org/10.1038/s41598-020-72800-2 (2020).

2. Wang, X. et al. Nanomaterials as sorbents to remove heavy metal ions in wastewater treatment. J. Anal. Toxicol. 2(7), 154-158 (2012).

3. Saif, S., Tahir, A. \& Chen, Y. Green synthesis of iron nanoparticles and their environmental applications and implications. Nanomaterials. 6(11), 209 (2016).

4. Elsayed, E. E. Natural diatomite as an effective adsorbent for heavy metals in water and wastewater treatment (a batch study). Water Sci. 32(1), 32-43 (2018).

5. Dargahi, A., Golestanifar, H., Darvishi, P., Karam, A. An investigation and comparison of removing heavy metals (lead and chromium) from aqueous solutions using magnesium oxide nanoparticles. (2015)

6. Renu, M. A., Singh, K., Upadhyaya, S. \& Dohare, R. Removal of heavy metals from wastewater using modified agricultural adsorbents. Mater. Today 4(9), 10534-10538 (2017).

7. Tripathi, A. \& Ranjan, M. R. Heavy metal removal from wastewater using low cost adsorbents. J. Bioremed. Biodeg. 6(6), 315 (2015).

8. Hu, J., Lo, I. M. \& Chen, G. Comparative study of various magnetic nanoparticles for $\mathrm{Cr}(\mathrm{VI})$ removal. Sep. Purif. Technol. 56(3), 249-256 (2007).

9. Barakat, M. New trends in removing heavy metals from industrial wastewater. Arab. J. Chem. 4(4), 361-377 (2011).

10. Azimi, A., Azari, A., Rezakazemi, M. \& Ansarpour, M. Removal of heavy metals from industrial wastewaters: A review. ChemBioEng Rev. 4(1), 37-59 (2017).

11. Sezgin, N., Sahin, M., Yalcin, A. \& Koseoglu, Y. Synthesis, characterization and the heavy metal removal efficiency of $\mathrm{MFe}_{2} \mathrm{O}_{4}(\mathrm{M}$ $=\mathrm{Ni}, \mathrm{Cu}$ ) nanoparticles. Ekoloji. 22(89), 89-96 (2013).

12. Ahamad, T. et al. Synthesis of a recyclable mesoporous nanocomposite for efficient removal of toxic $\mathrm{Hg} 2+$ from aqueous medium. J. Ind. Eng. Chem. 53, 268-275. https://doi.org/10.1016/j.jiec.2017.04.035 (2017).

13. Sadegh, H. et al. The role of nanomaterials as effective adsorbents and their applications in wastewater treatment. J. Nanostruct. Chem. 7(1), 1-14 (2017).

14. Pal, D. \& Maiti, S. K. An approach to counter sediment toxicity by immobilization of heavy metals using waste fish scale derived biosorbent. Ecotoxicol. Environ. Saf. 187, 109833 (2020).

15. Lu, H. et al. An overview of nanomaterials for water and wastewater treatment. Adv. Mater. Sci. Eng. 2016, 1-10 (2016).

16. Giraldo, L., Erto, A. \& Moreno-Piraján, J. C. Magnetite nanoparticles for removal of heavy metals from aqueous solutions: Synthesis and characterization. Adsorption. 19(2-4), 465-474 (2013).

17. Anjum, M., Miandad, R., Waqas, M., Gehany, F. \& Barakat, M. A. Remediation of wastewater using various nano-materials. Arab. J. Chem. 12, 4897-4919 (2016).

18. Sagadevan, S., Chowdhury, Z. Z. \& Rafique, R. F. Preparation and characterization of nickel ferrite nanoparticles via co-precipitation method. Mater. Res. 21(2), 10 (2018).

19. Ong, B., Chee, E., Abd Hamid, S., Lim, K. Synthesis and characterization of nickel ferrite magnetic nanoparticles by co-precipitation method. AIP Conf. Proc. (2012).

20. Zekić, E., Vuković, Ž \& Halkijević, I. Application of nanotechnology in wastewater treatment. Građevinar. 70(04), 315-323 (2018).

21. Abdelbasir, S. M. \& Shalan, A. E. An overview of nanomaterials for industrial wastewater treatment. Korean J. Chem. Eng. 36(8), $1209-1225$ (2019).

22. Masood, M. H., Haleem, N., Shakeel, I. \& Jamal, Y. Carbon dioxide conversion into the reaction intermediate sodium formate for the synthesis of formic acid. Res. Chem. Intermed. 1, 1-16 (2020).

23. Moradmard, H. \& Shayesteh, S. F. The variation of magnetic properties of nickel ferrite by annealing. Manuf. Sci. Technol. 3(4), $141-145$ (2015).

24. Phul, R., Khan, M. A. M., Sardar, M., Ahmed, J. \& Ahmad, T. Multifunctional electrochemical properties of synthesized nonprecious iron oxide nanostructures. Crystals. 10(9), 751. https://doi.org/10.3390/cryst10090751 (2020).

25. Yang, J. et al. Nanomaterials for the removal of heavy metals from wastewater. Nanomaterials. 9(3), 424 (2019).

26. Jamal, Y., Luo, G., Kuo, C. H., Rabie, A. \& Boulanger, B. O. Sorption kinetics, thermodynamics and regeneration for lipid feedstock deacidification using a mixed-bed ion-exchange resin. J. Food Process. Eng. 37(1), 27-36 (2014).

27. Younas, H. et al. Visible light photocatalytic water disinfection and its kinetics using Ag-doped titania nanoparticles. Environ. Sci. Pollut. Res. 21(1), 740-752 (2014).

28. Jin, S. \& Wang, D. Molecular structure of five inorganic-organic hybrid crystals from $\mathrm{N}$-containing aromatic bases and perchlorometallates of $\mathrm{Cd} 2+, \mathrm{Co} 2+, \mathrm{Cu} 2+$, and $\mathrm{Zn} 2+$. Synth. React. Inorg., Met.-Org., Nano-Met. Chem. 43(5), 562-574. https://doi. org/10.1080/15533174.2012.749894 (2013).

29. Manimozhi, V., Partha, N., Sivakumar, E., Jeeva, N. \& Jaisankar, V. Preparation and characterization of ferrite nanoparticles for the treatment of industrial waste water. Digest J. Nanomater. Biostruct. 11(3), 1017-1027 (2016).

30. Almomani, F., Bhosale, R., Khraisheh, M. \& Almomani, T. Heavy metal ions removal from industrial wastewater using magnetic nanoparticles (MNP). Appl. Surf. Sci. 506, 144924. https://doi.org/10.1016/j.apsusc.2019.144924 (2020).

\section{Acknowledgements}

The authors gratefully acknowledge National University of Science and Technology (NUST), for providing financial support and facilities required to carry out this work. We are also thankful to Engr. Jawwad Ahmed of Prime chemical corporation (Pvt) Ltd. Islamabad, for his valuable suggestions and critical comments.

\section{Author contributions}

W.A.K. and N.H. wrote the main manuscript text, Dr. M.A.B. \& N.H. prepared figures and Dr. Y.J. helped in write up of the manuscript. All authors have reviewed the manuscript.

\section{Competing interests}

The authors declare no competing interests.

\section{Additional information}

Correspondence and requests for materials should be addressed to N.H.

Reprints and permissions information is available at www.nature.com/reprints.

Publisher's note Springer Nature remains neutral with regard to jurisdictional claims in published maps and institutional affiliations. 
(c) (i) Open Access This article is licensed under a Creative Commons Attribution 4.0 International cc) License, which permits use, sharing, adaptation, distribution and reproduction in any medium or format, as long as you give appropriate credit to the original author(s) and the source, provide a link to the Creative Commons licence, and indicate if changes were made. The images or other third party material in this article are included in the article's Creative Commons licence, unless indicated otherwise in a credit line to the material. If material is not included in the article's Creative Commons licence and your intended use is not permitted by statutory regulation or exceeds the permitted use, you will need to obtain permission directly from the copyright holder. To view a copy of this licence, visit http://creativecommons.org/licenses/by/4.0/.

(C) The Author(s) 2021 